We welcome letters to the Editor concerning articles which have recently been published. Such letters will be subject to the usual stages of selection and editing; where appropriate the authors of the original article will be offered the opportunity to reply.

Letters should normally be under $\mathbf{3 0 0}$ words in length, doublespaced throughout, signed by all authors and fully referenced. The edited version will be returned for approval before publication.

(C)2006 British Editorial Society of Bone and Joint Surgery

\$2.00 J Bone Joint Surg [Br] 2006;88-B:1264-6.

\section{Levels of evidence}

Sir,

We read with interest the three editorials ${ }^{1-3}$ on levels of evidence published in the December 2005 issue. Mr Horan accurately states that surgeons provide optimal care to patients based on a combination of clinical expertise and 'best available evidence'. ${ }^{1}$ Herein, however, lies the crux of the problem. The surgical literature very often does not agree, and this disagreement is reflected in a wide variety of treatments for the same clinical condition. Unless all the available interventions have the same risks and benefits, we (or more importantly our patients), have a problem.

To resolve clinical controversies, surgeons must sort through and evaluate the conflicting evidence. Some studies are better designed and those studies provide more compelling information. For example, surgeons recognise that controlled studies, compared with uncontrolled case series, provide more convincing data; prospective is more reliable than retrospective data collection; and randomisation is the most valid way to minimise those factors that influence the outcome of treatment other than the intervention. These universally-accepted principles are the essence of levels of evidence.

Levels of evidence, introduced in the American Journal of Bone and Joint Surgery in January $2003,{ }^{4}$ are a simple and intuitive guide to help surgeons quickly appraise the myriad of published studies to assemble the 'best available evidence'. Levels of evidence are now also used by the Journal of Hand Surgery, Clinical Orthopaedics and Related Research, Arthroscopy, the American Journal of Sports Medicine, and the Journal of the American Academy of Orthopaedic Surgeons. Grades of recommendation, based on levels of evidence and used to summarise the quality of literature, were introduced in July 2005..$^{5}$ Although not considering all aspects of research design, levels of evidence have been shown to be reliable ${ }^{6}$ and moreover, those journals that publish articles with higher levels of evidence have higher impact factors. ${ }^{7}$

All levels of evidence are useful. ${ }^{2}$ For example, John Charnley's case series fundamentally changed the practice of orthopaedics. ${ }^{8}$ Total hip replacement is the 'parachute' of orthopaedics - a randomised trial was not required to demonstrate its superiority. Unfortunately most treatments in orthopaedics are not so obvi- ously beneficial as total hip replacement - otherwise why would there be the thousands of different prostheses and techniques? Messrs. Horan and Carr both comment on the unique challenges of performing randomised trials in orthopaedics. ${ }^{1,3}$ Most of their issues are surmountable. ${ }^{9}$ More importantly, however, just because trials are challenging does not mean we should not try. Case series are unable to solve most of the current treatment controversies. Only with controlled, prospective, and hopefully randomised clinical studies can we resolve these clinical dilemmas and thereby fulfil our promise to provide patients with optimal care. doi:10.1302/0301-620X.88B9.18389

J. G. WRIGHT, MD, MPH, FRCSC, Associate Editor Evidence-Based Orthopaedics M. SWIONTKOWSKI, MD,

Deputy Editor for Outcome Studies and Trauma J. D. HECKMAN, MD, Editor in Chief, Journal of Bone and Joint Surgery [Am]

1. Horan FT. Judging the evidence. J Bone Joint Surg [Br] 2005;87-B:1589-90.

2. Tovey D, Bognolo G. Levels of evidence and the orthopaedic surgeon. J Bone Joint Surg [Br] 2005;87-B:1591-2.

3. Carr AJ. Evidence-based orthopaedic surgery: what type of research will best improve clinical practice? J Bone Joint Surg [Br] 2005;87-B:1593-4.

4. Wright JG, Swiontkowski F, Heckman JD. Introducing levels of evidence to the journal. J Bone Joint Surg [Am] 2003;85-A:1-3.

5. Wright JG, Einhorn TA, Heckman JD. Grades of recommendation. J Bone Joint Surg [Am] 2005;87-A:1909-10.

6. Bhandari M, Swiotkowski MF, Einhorn TA, et al. Interobserver agreement in the application of levels of evidence to scientific papers in the American volume of the Journal of Bone and Joint Surgery. J Bone Joint Surg [Am] 2004;86-A:1717-20.

7. Obremskey WT, Pappas N, Attallah-Wasif E, Tornetta Pr, Bhandari M. Level of evidence in orthopaedic journals. J Bone Joint Surg [Am] 2005;87-A:2632-8.

8. Charnley J. The long-term results of low-friction arthroplasty of the hip performed as a primary intervention. J Bone Joint Surg [Br] 1972;54-B:61-76.

9. McLeod RS, Wright JG, Solomon MJ, et al. Randomized controlled trials in surgery: issues and problems. Surgery 1996;119:483-6.

Sir,

I am writing to say how much I enjoyed reading the editorials ${ }^{1-3}$ on levels of evidence in orthopaedic surgery that were published in the December 2005 issue. As with the scientific articles in the British edition, these editorials were succinct and very informative, and contained a lot of common sense in evaluating these hot button issues' of levels of evidence in scientific publications as well as the concept of evidence-based practice as it applies to orthopaedic surgery.

With regard to levels of evidence, so much nonsense has been written about the need for randomised controlled trials (RCTs) when in fact there is no hope that these can really occur to any extent in a surgical field. It is neither ethical nor practically possible to conduct studies of this type when evaluating surgical procedures. As was pointed out in the articles, it would be difficult to do a 'sham' operation, not withstanding the fact that it would be unethical. Therefore, having some sort of prospective blinded study is virtually impossible in the surgical field and it is time that we stopped discussing it. What we can do however, is design pro- 
spective and retrospective studies as conscientiously as possible and try to retain the patients in the cohort groups, and to have as good a follow-up on those patients as possible, so that any data that can emanate from such studies will be the best it can be. Studies in which half the patients were lost to follow-up always make drawing conclusions somewhat worrisome despite the fact that these studies usually have some analysis of the 'lost to follow-up patients', regarding their demographic and other information. Again, as was pointed out in these articles, so many advances have occurred in the development of procedures and implants over the recent decades that have made our patients lives so much better. The information that we have on these new inventions and treatments for the most part have been retrospective studies that compare the new treatment with more standard treatments from the past. One only has to look at the results of total hip replacement to realise the huge positive impact this has had on patients with arthritis of the hip and the improvement in their quality of life. While the evidence level in various articles published on the subject may not reach level I, certainly enough useful information has emanated from retrospective studies to refine and improve implants and techniques. Various pundits criticise the lack of RCTs for surgical procedures and seem to indicate that if they existed, the information provided and the conclusions reached would be somehow 'more true' than those that emanate from a retrospective study. Yet, there are a number of recent examples of RCTs that involved various drugs that have been erroneous, and designing and conducting a RCT does not ensure that the study was done correctly and without bias.

With regard to evidence-based practice, it is not a new concept. Various groups have adopted this catchy term when in fact all of us use evidence-based medicine every day in evaluating patients and deciding the appropriate treatment for them. I cannot think of any day that goes by in which I do not weigh various treatment options based on what I have read and my own experience in trying to come up with the best recommendation for my patients. Evidence-based practice is an overworked concept whose proponents would like the public to think that this is something new and different and is going to revolutionise what we do, when in fact the concept is as old as Hippocrates.

Thank you for presenting these three editorials and I hope that the powers that be that are trying to force these concepts on the rest of us will somehow temper their enthusiasm based on the reality and practicality of the issues. In the end, whatever is done or whatever concept is adopted depends largely on the conscience and honesty of the investigators. Studies that are conducted with industry support and have virtually unmasked bias cannot be relied on as providing truthful information, even though they may be designed as prospective studies, unless the integrity of the investigators is beyond reproach. Designing a study a certain way does not necessarily ensure its verisimilitude. It is also time for courageous practitioners and editors of major journals to challenge some of these supposedly new concepts and I think that you and the British journal should be congratulated on having done this with the publication of these three editorials.

doi:10.1302/0301-620X.88B9.18309

J. P. LUBICKY, MD, FAAOS, FAAP

Department of Orthopaedic Surgery,

Indiana University, Medical Center/Riley Hospital for Children, Indianapolis, USA.

1. Carr AJ. Evidence-based orthopaedic surgery: what type of research will best improve clinical practice? J Bone Joint Surg [Br] 2005;87-B:1593-4.
2. Horan FT. Judging the evidence. J Bone Joint Surg [Br] 2005;87-B:1589-90.

3. Tovey D, Bognolo G. Levels of evidence and the orthopaedic surgeon. J Bone Joint Surg [Br] 2005;87-B:1591-2.

Sir,

We read with interest the three editorials in the December 2005 issue $^{1-3}$ regarding clinical levels of evidence and the orthopaedic surgeon. They highlight the difficulty in producing meaningful data from randomised controlled trials (RCTs) in the context of surgical practice. Whereas our physician colleagues have embraced RCTs as the basis of much of their evidence-based practice, due to the relative ease in removing most bias in the delivery of pharmacological therapy, this is not practical for surgical intervention and especially not with regards to relatively more complex procedures. The delivery of surgical care is by its very nature subject to variation due to a number of factors such as experience, local facilities, population mix and individual interpretation. Hence, extremely good survival rates of various prostheses are often reported, by individual, experienced surgeons, that are not often reproducible in the wider context. ${ }^{4}$ More informative sources on the effect of current practice and newly-accepted practices in the wider context of orthopaedic surgery at the local, regional and national level may be well-constructed and funded, prospective cohort studies and registers (level II evidence), ${ }^{1}$ recognise that for various reasons there will always be differences in aspects of practice that cannot be effectively addressed by RCTs, but yet can easily acquire numbers that render them statistically significant. Of course, the best example of this so far is the number of national joint registries in existence. RCTs can be constructed effectively to demonstrate useful differences in surgical practice, but surgeons should realise that just because one method of treating patients can show effective differences by the relatively simple practice of changing drug regimes, which has elevated RCTs to their current state as the holy grail of research, this may not be wholly appropriate, applicable or accurate in assessing surgical practice.

doi:10.1302/0301-620X.88B9.17684

M. H. A. MALIK, MA, MRCS (Trauma \& Orthopaedics)

Consultant Lower Limb Surgeon, Arrowe Park Hospital, and Honorary Lecturer, University of Manchester, UK.

A. GAMBHIR, FRCS, FRCS (Trauma \& Orthopaedics)

M. L. PORTER, FRCS, FRCS (Trauma \& Orthopaedics)

Wrightington Hospital,

Lancashire, UK.

1. Horan FT. Judging the evidence. J Bone Joint Surg [Br] 2005;87-B:1589-90.

2. Tovey D. Bognolo G. Levels of evidence and the orthopaedic surgeon. J Bone Joint Surg [Br] 2005;87-B:1591-2.

3. Carr AJ. Evidence-based surgery: what type of research will best improve clinical practice? J Bone Joint Surg [Br] 2005;87-B:1593-4.

4. Furnes $\mathbf{0}$, Lie SA, Espehaug B, et al. Hip disease and the prognosis of total hip replacements: a review of 53,698 primary total hip replacements reported to the Norwegian Arthroplasty Register 1987-99. J Bone Joint Surg [Br] 2000;83-B:579-87.

\section{Judging the evidence}

Sir,

I read with interest the editorial by Horan ${ }^{1}$ in the December 2005 issue entitled 'Judging the evidence'. Through a subspecialty in orthopaedic surgery, I have been the participant and designer of randomised prospective studies for the prevention of deep venous thrombosis in orthopaedic surgery. The reason for conducting randomised prospective studies is obvious, but as Mr Horan has 
pointed out, it is difficult and sometimes impossible to carry out high-quality randomised controlled studies, particularly with respect to a new surgical operative method. In this case, the best that can be done is that of a level III study of a retrospective comparative nature; or even level IV or V. That is not to say that those studies are not valuable, but it reinforces the nature of the study for the benefit of the reader. There is no way for an editor to check on the truthfulness of a cohort study and he must at best take the word of the author. As in politics, occasionally a so-called 'giant' in the field may exaggerate his findings, particularly if he is an inventor of a new surgical procedure.

I agree that it is our function to provide the highest quality of information, and that is the reason that I read both the American and the British Journal of Bone and Joint Surgery. By adding levels of evidence, I believe that we help the reader's understanding of the study type. I find the author's last analogy intriguing, and would therefore put forth this question: if you had the opportunity to judge five different parachutes that were evaluated in a prospective, randomised nature, would you choose the best, or would you take it on blind faith that a 'giant' in the parachute world told you the parachute would indeed work?

doi:10.1302/0301-620X.88B9.18394

C. W. COLWELL, JR., MD,

Director, Shiley Center for Orthopaedic Research and Education at Scripps Clinic,

California, USA.

1. Horan FT. Judging the evidence. J Bone Joint Surg [Br] 2005;87-B:1589-90.

$\because$ Two further letters from Dr. Colwell on this subject are C available as supplementary material at www.jbjs.org.uk 